\title{
OCCURRENCE OF Cryptosporidium sp INFECTION IN INDIVIDUALS INFECTED BY HIV, SICK OR NOT, TREATED AT THE UNIVERSITY HOSPITAL, BOTUCATU SCHOOL OF MEDICINE - UNESP
}

THESIS. G. Langoni Junior submitted this thesis for his Doctorate in Tropical Diseases at Botucatu School of Medicine, São Paulo State University, UNESP, Botucatu, São Paulo, Brazil, 2004.

Advisor: Professor Lenice do Rosário de Souza

\begin{abstract}
The objective of this work was to evaluate Cryptosporidium sp infection in HIV or AIDS patients treated at Botucatu University Hospital, Scholl of Medicine, UNESP - São Paulo. One hundred and five patients were evaluated and divided into groups by CD4+T lymphocyte count of more or less than $200 \mathrm{cells} / \mathrm{mm}^{3}$, and with or without potent antiretroviral treatment. Between July 2002 and September 2003, we examined two stool samples from each patient. These samples were fixed in $10 \%$ formalin and sent to the Tropical Diseases Laboratory. They underwent centrifugal sedimentation by formaldehyde-ether. Slides were stained with auramine and confirmed by Zihel-Neelsen modified technique. Occurrence of Cryptosporidium sp was $10.5 \%$. There was no relation between sex, age, and diarrhea in the 11 cryptosporidiosis patients in this study. No positive stool sample patient lived in the rural area. The number of oocysts was small in all analyzed samples regardless of CD4+T lymphocyte count, HIV plasmatic viral load, and presence of diarrhea. This was also small in the only patient who had not received antiretroviral treatment. This may be justified by the general decrease of opportunistic infections, and specifically cryptosporidiosis, after starting potent antiretroviral therapy.
\end{abstract}

KEY WORDS: Cryptosporidium sp, AIDS.

\section{CORRESPONDENCE TO:}

G. LANGONI JÚNIOR, Departamento de Doenças Tropicais e Diagnóstico por Imagem, Faculdade de Medicina de Botucatu, UNESP, Distrito de Rubião Junior, s/n, 18618-000, Botucatu, SP, Brasil. Phone: 55143811 6212. Email: Isouza@fmb.unesp.br 